\title{
Siyanoakrilat ile safen ven embolizasyonunda ortalama trombosit hacmi ve trombosit sayısının değişimi
}

\section{The change of average platelet volume and platelets count in saphenous vein embolization using by cyanoakrilate}

\author{
Cengiz Güven ${ }^{\mathbb{D}}$, Mevlüt Doğukan² ${ }^{2}$ \\ ${ }^{1}$ Adıyaman Üniversitesi Tıp Fakültesi, Kalp ve Damar Cerrahisi Anabilim Dalı, Adıyaman, Türkiye \\ ${ }^{2}$ Adıyaman Üniversitesi Tıp Fakültesi, Anestezi ve Reanimasyon Anabilim Dalı, Adıyaman, Türkiye
}

Öz.

Amaç: Bu çalışmada amacımız kronik venöz yetmezlik ve varis tedavisinde siyanoakrilat (CA) ile yapılan safen ven embolizasyonunda işleme bağlı ortalama trombosit hacminin (MPV) ve trombosit sayısının değişimini saptamak ve oluşabilecek venöz tromboembolizm olaylarına açıklık getirmektir.

Materyal ve Metot: Bu çalışmaya dâhil edilen 60 hasta Adıyaman Üniversitesi Tıp Fakültesi Kalp ve Damar Cerrahisine Polikliniğine başvuran varis ve kronik venöz yetersizliği olan hastalardan seçildi. CA ile safen ven embolizasyonu yapılan hastaların dosya taraması dijital ortamda yapılarak USG ve laboratuvar tetkikleri incelendi. İşlem yapılan toplam 437 hastadan işlem öncesi ve sonrası hemogram ve biyokimya tetkikleri alınan60hasta çalışmaya dahil edildi. Hastaların işlem öncesi ve sonrası trombosit sayısı ve ortalama trombosit hacmi değerlendirildi.

Bulgular: Postoperatif(post-op) 1. Saat ve 1.ay MPV değeri preoperatif (pre-op) döneme göre anlamlı ( $p>$ $0.05)$ değişim göstermezken post-op 3.gün MPV değeri pre-op döneme göre anlamlı $(p<0.05)$ artış gösterdiği tespit edildi. Post-op 3.gün MPV değeri post op 1.saate göre anlamlı $(p<0.05)$ artış ve post-op 1.ay MPV değeri post-op 3.güne göre anlamlı $(p<0.05)$ düşüş göstermiştir.

Sonuç: MPV işlemden 1 gün sonra normal değerlerden anlamlı artış göstermez iken post op 3. günde anlamlı artış gösterdi. MPV'ün artan trombojenite ile ilişkili olduğunu varsayarsak varis tedavisinde kullanılan minimal invaziv yöntemlerden olan CA ile safen ven embolizasyonu post-op erken (Illk bir hafta içinde) dönemde tromboembolik olaylara sebep olabilmektedir.

Anahtar kelimeler: Mean platelet volüm, Varis, Siyanoakrilat, Tromboembolizm

\section{Abstract}

Background: In the present study, it is aimed to determine the intervention-related change in the mean platelet volume (MPV) and platelet count in saphenous vein embolization performed using cyanoacrylate in chronic venous stasis and varicose treatment, as well as explaining the possible venous thromboembolism events.

Methods: 60 patients involved in the present study were selected from the patients, who had varicose and chronic venous stasis and who applied to the Cardiovascular Surgery Polyclinic of Medical Faculty of Adıyaman University. The files of patients undergone saphenous vein embolization using CA were performed digitally and their USG and laboratory results were analyzed. Among 437 patients, 60 patients' undergone hemogram and biochemical examination before and after the intervention were involved in the present study. The preoperative (pre-op) and postoperative (post-op) platelet counts and mean platelet volumes of the patients were analyzed. Results: When compared to the pre-op period, no significant change was observed on $1^{\text {st }}$ post-ophour and

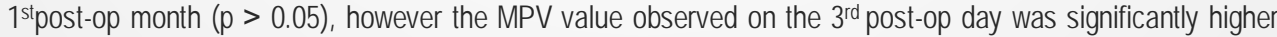
than the pre-op period $(p<0.05)$. The MPV value observed on the $3^{\text {rd }}$ post-op day was statistically higher than on $1^{\text {st }}$ post-op hour $(p<0.05)$ and the MPV value observed on the $1^{\text {st }}$ post-op month was statistically significantly lower than on $3^{\text {rd }}$ post-op day $(p<0.05)$.

Conclusion: MPV did not significantly increase from the normal values on the $1^{\text {st }}$ postoperative day, whereas it significantly increased on the $3^{\text {rd }}$ postoperative day. Assuming that MPV is related with the increasing thrombogenicity, it can be stated that the saphenous vein embolization by using CA that is one of the minimally invasive methods used in varicose treatment may cause thromboembolic events in the early pre-op period (in the first week).

Keywords: Mean platelet volume, Varicose, Cyanoacrylate, Thromboembolism

\section{Sorumlu Yazar I \\ Corresponding Author}

Dr. Cengiz GÜVEN

Adıyaman Üniversitesi Tıp Fakültesi KVC AD. Klinik Sekreterliği/ Adıyaman

Tel: +90505454 0473

e-mail: guvencengz@yahoo.com

Geliş tarihi / Received: 01/03/2019

Kabul tarihi / Accepted: 23/07/2019

DOI: $10.35440 /$ hutfd. 534120 


\section{Giriş}

Kronik venöz yetmezlik ve buna bağlı oluşan varis, toplumda sık karşılaşılan ve yüksek morbidite ile seyreden bir hastalıktır. 18-64 yaş arası nüfusun yaklaşık 1/3'ünde KVY ne bağlı varis görülmektedir (1).

Varis çorabı ve ilaç tedavisi gibi konservatif yöntemlerle tedavi edilen varis,ileri aşamalarda uzun yıllar boyunca altın standart olan cerrahi ile tedavi edilmiştir. Ancak özellikle son 15-20 yılda halk arasında ameliyatsız yöntem olarak tanımlanan ve renkli venözdopler ultrasonografi (RVDUSG)'ninde kullanımı ile endovenöz lazer ablasyon (EVLA) ve radyo frekans ablasyon (RFA) gibi yeni yöntemlerin kullanılması tedavide çığır açmıştır (2).

Bu yöntemlerin en önemli dezavantajı tüm esan anestezi gibi ağrıı multipl perivenöz enjeksiyonlardır. Fakat son dekatta ortaya çıkan CA ile safen ven embolizasyonu bu sorunu ortadan kaldırmışıı. Tüm minimal invaziv yöntemlerde olduğu gibi bu yöntemde de direk damar içerisine gönderilen bazı enstrümantal cihazlar venöz tromboemboliyi tetikleyebilmektedir.

Trombositlerin kardiyovasküler hastalıkların patogenezinde çok önemli bir rol oynadığı bilinmektedir. Trombositler boyut ve aktivite bakımından heterojendir(3). Daha büyük trombositler daha yoğundur ve vasküler neointimal proliferasyona katkıda bulunan kemotaktik ve mitojenik faktörler içerir $(4,5)$.

MPV trombosit büyüklüğünün en sık kullanılan ölçüsüdür, ucuz ve kullanımı kolay bir belirtecidir $(6,7)$. Literatürde yapılan birçok çalışmada artmış MPV düzeylerinin artmış trombosit aktivitesinin bir göstergesi olarak bulunmuştur. Ancak MPW ile Platelet arasında ters bir ilişki vardır. Yani artmış MPW azalmış Platelet sayısıyla ilişkilidir(8-10).

Varis hastalarında özellikle ileri evre hastalarda DVT ve tromboemboliye meyli artığı bilinmektedir. Variköz pakelerde kan akımının çok yavaşlaması ve tirbülansa uğraması pıhtılaşma mekanizmasını aktive edebilir. Olay flebotromboza hatta ağrılı bir klinik durum olan tromboflebite ilerler. Tedavide gecikmiş olan hastalarda venöz yatakta oluşan pıntıların koparak pulmoneremboliye sebep olması mortal bir klinik tabloya sebep olur. Ancak zamanında yapılan uygun müdahale ile tedavi edilen hastalarda bu klinik durumlara progresyonu önlenebilir.

Bizim bu çalışmadaki esas amacımız varis tedavisinde minimal invaziv yöntemlerden olan CA ile safen ven embolizasyonunun MPVvetrombositlerdesayısal değişikliğe sebep olup olmadığını ortaya koymaktır. Hastaların pre-op ve post-op MPV değerleri karşılaştıılarak varis tedavisinin trombojeniteye etkisini ortaya koymaya çalıştık.

\section{Materyal ve Metot}

Hastalar 26.06.2018-31.12.2018tarihleri arasında AdıyamanÜniversitesi Tıp Fakültesi Kalp ve Damar Cerrahisi Polikliniğine başvuran varis veya KVY (Kronik Venöz Yetmez- lik)'li hastalardan seçildi. Çalışma retrospektif olarak yapıldı. Veriler dijital ortamda hasta dosyaları incelenerek toplandı. İncelenen toplam 437 hastadan Pre-op ve postop laboratuvar tetkikleri alınan 60 hasta çalışmaya dâhil edildi. Çalışmaya dâhil edilen hastaların laboratuar tetkikleri incelenerek işlem öncesi ve sonrası MPV değerleri ve diğer parametreler karşılaştırıldı.

Akut veya kronik DVT öyküsü olan, herhangi bir sebeple antikoagulan ilaç kullanan, eşlik eden periferik arter hastalığı bulunan, gebelik ve emziren anneler, konjenital trombositoz veya trombositopeni ile seyreden hastalığı olanlar, aktif enfeksiyonu ve diyabeti bulunan hastalar çalışmaya dâhil edilmedi. $20 \mathrm{~mm}$ den büyük safen ven çapı diğer dışlama kriteri olarak alındı. Bacak semptomları VCSS (Venöz Klinik Şiddet Skoru) ve CEAP (Clinical, Etiolojic, Anatomic, Pathophysiologic) klinik skoru ile değerlendirildi.

MPV ve diğer hematolojik parametrelerin ölçümleri için tüm kan örnekleri EDTA içeren tüplerde toplandı. Bu kan örnekleri, işlemden önce hastanede yatış sırasında bir gece aç kaldıktan sonra sabah alındı. Tüm örnekler Cell DynRuby kan sayım cihazı ile 30-60 dakika arasında çalışıldı. Tüm ölçümler için varyasyon (interassay) katsayıları $<\% 5$ idi.

Tüm hastaların hemoglobin, hematokrit, nötrofil (NEU), lenfosit (LYM), MPV, trombosit sayıSI (PLT) ve trombosit dağılım genişliği (PDW) düzeyleri dahil olmak üzere geniş hematolojik analizleri incelendi.

Prosedürel İşlem: USG eşliğinde lokal anestezi altında seldinger tekniği ile safen ven diz üstü seviyesinde ponksiyon yapıldı. Sheath yerleştiridi. Guide eşliğinde teslim katateri sheath üzerinden safenofemoral bileşkenin yaklaşık 2-3 cmdistaline kadar ilerletildi. Daha sonra doku yapıştırICISI CA safenofemoral bölgeden USG probu ile kompresyon uygulanarak teslim katateri saniyede $2 \mathrm{~cm}$ çekilerek otomatik tabanca ile verildi. İşlemden sonra masada yapıIan USG kontrolünde tüm hastalarda safenvenin kapandığı görüldü. İşlemden sonra tüm hastalar 3 saat içinde 24 saat kalmak üzere ilgili extremite elastik bandaja sarılarak taburcu edildi.

İstatistik: İstatistiksel analizler SPSS 22,0 kullanılarak yapıldı. Değişkenlerin dağılımı Kolmogorov-Simirnov testi kullanıldı. Verilerin tanımlayıcı istatistiklerinde ortalama, standart sapma, medyan, en düşük, en yüksek, frekans ve oran değerleri kullanıldı. Bağımlı nicel verilerin analizinde Wilcoxon testi kullanıldı. P değeri $<0,05$ istatistiksel olarak anlamlı kabul edildi.

\section{Bulgular}

Toplam 437 hastadan preop ve postop laboratuar değeri bulunan 60 hasta (18 erkek ve 42 kadın) çalışmaya dâhil edildi. Yaş ortalaması 42,4 \pm 11,3( min:26,0-max:76,0) idi (Tablo 1). 
Tablo1. Yaş ve Cinsiyete Göre Hasta Dağılımı

\begin{tabular}{lccc}
\hline & Min-Max & Medyan & Ortıss $/ \mathrm{n}-\%$ \\
\hline Yaş & $26,0-76,0$ & 40,0 & $42,4 \pm 11,3$ \\
\hline \multirow{2}{*}{ Cinsiyet } & Erkek & 18 & $30,0 / \%$ \\
& Kadın & 42 & $70.0 \%$ \\
\hline
\end{tabular}

Hastalara ait preop VCSS;6,6 $\pm 1,03$ iken postop VCSS; $1,7 \pm 0,7$ olarak bulundu (Tablo-2). Bu değerler yapılan işlemin başarısını gösteriyordu. Hastalar da işlem öncesi mevcut olan ağrı ve ödem şikâyetleri azalmış veya kaybolmuş olduğu görüldü.

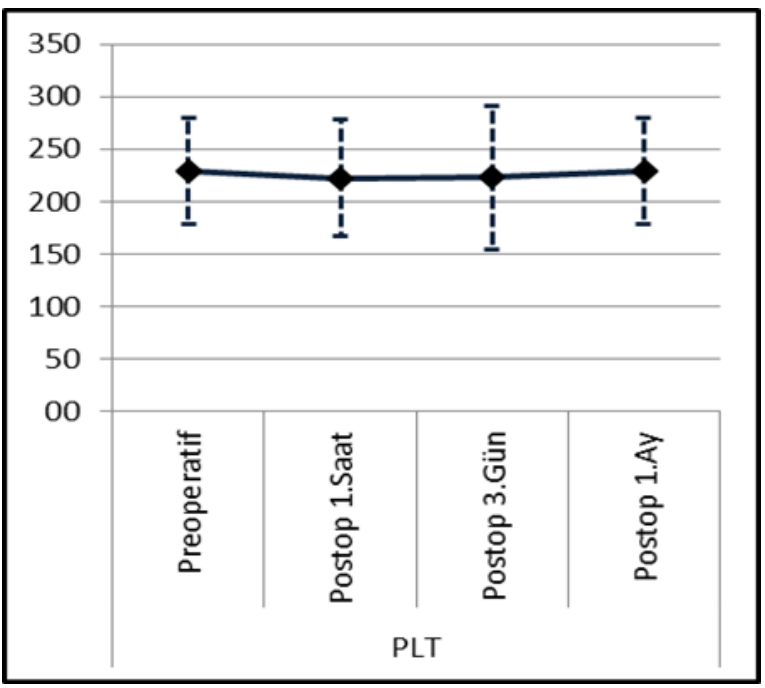

Şekil 1. Pre-op ve Post-op PLT Değişimleri PLT:Platelet

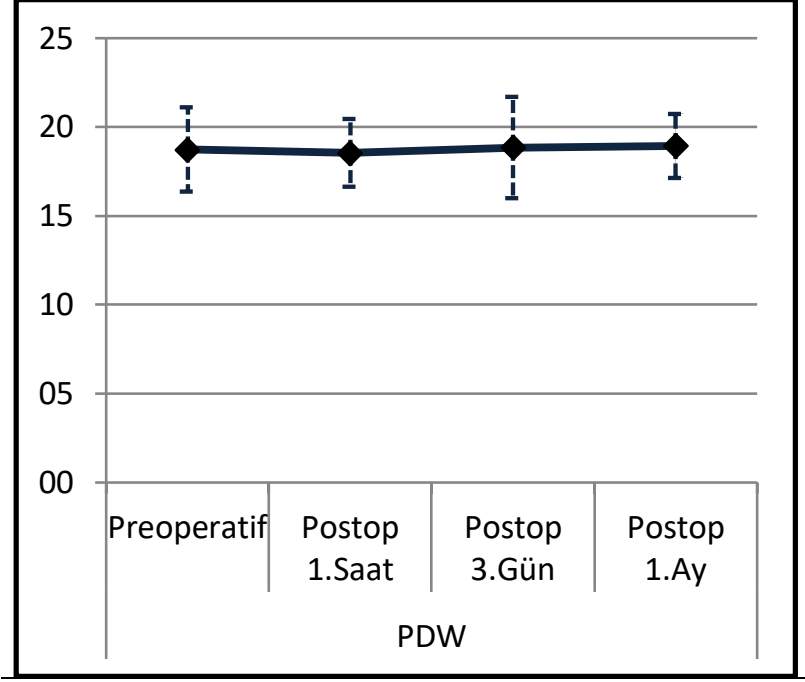

Şekil 2. Pre-op ve Post-op PDW Değişimleri PDW:Platelet Distribution Width

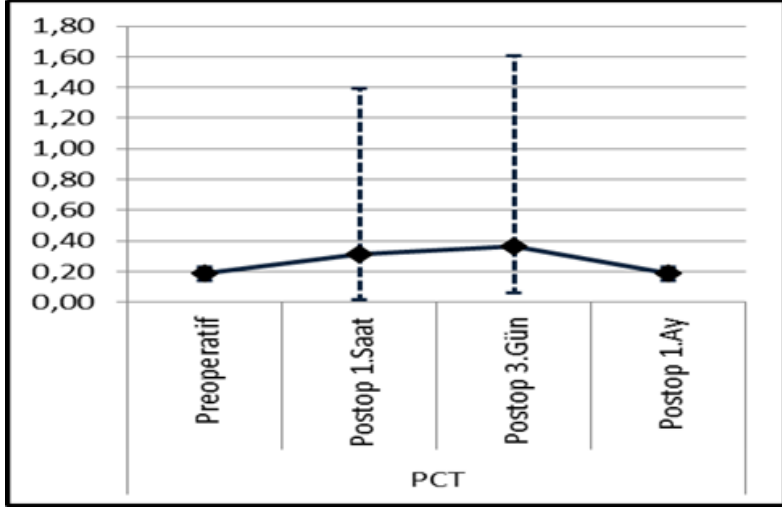

Şekil 3. Preop ve Postop PCT (Plateletcrit) Değişimleri

Tablo 2. Hastaların Pre op CEAP Klinik Skorları ve Pre ve post op VCSS ları

\begin{tabular}{lcc}
\hline $\begin{array}{l}\text { VCSS-CEAP Kli- } \\
\text { nik Skoru }\end{array}$ & & Ort. $\pm \mathrm{ss.} / \mathrm{n}-\%$ \\
\hline VCSS & (Pre op) & $6,6 \pm 1,1$ \\
& & $1,7 \pm 0$, \\
(P<0,05) & (Postop) & 7 \\
\hline & 2 & $15-25 \%$ \\
CEAP-Klinik & 3 & $41-.3 \%$ \\
Skoru & $4 \mathrm{a}$ & $3-5 \%$ \\
(Pre op) & $4 \mathrm{~b}$ & $1-, 7 \%$ \\
\hline VCSS: Venöz Klinik Şiddet Skoru, CEAP:Klinik, Etyolojik,Anatomik, Pa- \\
tolojik
\end{tabular}

Hastalara ait preop ve postop laboratuar tetkikleri Tablo3'de özetlenmiştir.

Pos-top 1. Saat NEU değeri pre-op döneme göre anlamlı ( $p>0.05$ ) değişim göstermemiştir. Post-op 3.gün NEU değeri pre-op döneme göre anlamlı $(p<0.05)$ artış gösterirken pos-top 1.ay NEU değeri pre-op döneme göre anlamlı $(p<0.05)$ düşüş göstermiştir. Postop 3.gün NEU değeri post-op 1.saate göre anlamlı $(p<0.05)$ artış göstermiş ve post-op 1.ay NEU değeri post-op 3.güne göre anlamlı ( $p<$ 0.05 ) düşüş göstermiş̧ir (Tablo 4)

Post-op 1. Saatteki $L Y M$ değeri pre-op döneme göre anlamlı ( $p>0.05)$ değişim göstermemiştir. Post-op 1.ay LYM değeri pre-op döneme göre anlamlı $(p<0.05)$ düşüş göstermiştir. Postop 3.gün LYM değeri postop 1.saate göre anlamlı $(p>0.05)$ değişim göstermemiştir. Postop 1.ay $L Y M$ değeri postop 3.güne göre anlamlı $(p<0.05)$ düşüş göstermiştir (Tablo 4). 
Tablo 3: Hastaların Preoperatif ve Postoperatif Laboratuar Verileri

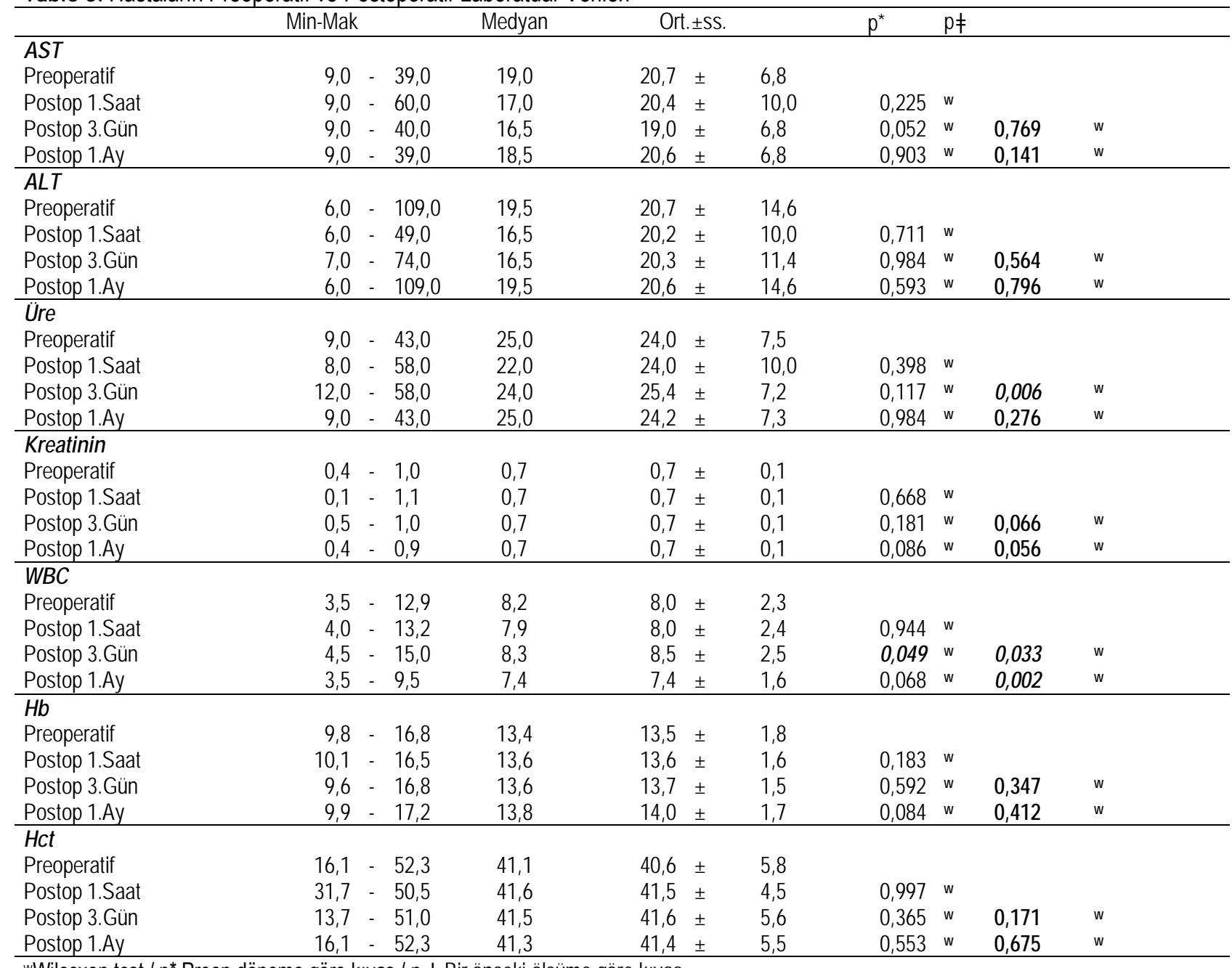

wWilcoxon test $/ p^{*}$ Preop döneme göre kıyas / $p$ キ Bir önceki ölçüme göre kıyas

Tablo 4. Pre-op ve Post-op NEU ve LYM değişimleri

\begin{tabular}{|c|c|c|c|c|c|}
\hline & Min-Mak & Medyan & Ort. \pm ss. & $p^{*}$ & $p \neq$ \\
\hline \multicolumn{6}{|l|}{ NEU } \\
\hline Preoperatif & $1.8-10.0$ & 4.3 & $4.6 \pm 2.0$ & & \\
\hline Postop 1.Saat & $1.9-10.8$ & 4.4 & $4.6 \pm 1.8$ & $0.508 w$ & \\
\hline Postop 3.Gün & $2.0-10.0$ & 4.7 & $5.2 \pm 2.0$ & $0.021 w$ & $0.026^{w}$ \\
\hline Postop 1.Ay & $1.8-7.7$ & 4.0 & $4.0 \pm 1.4$ & $0.001 w$ & $0.000^{w}$ \\
\hline \multicolumn{6}{|l|}{$L Y M$} \\
\hline Preoperatif & $1.4-4.3$ & 2.3 & $2.4 \pm 0.8$ & & \\
\hline Postop 1.Saat & $1.1-7.1$ & 2.3 & $2.5 \pm 1.0$ & $0.962 w$ & \\
\hline Postop 3.Gün & $0.4-4.2$ & 2.4 & $2.5 \pm 0.8$ & $0.260 w$ & $0.383^{w}$ \\
\hline Postop 1.Ay & $1.4-4.0$ & 2.1 & $2.3 \pm 0.7$ & $0.006 w$ & $0.005^{w}$ \\
\hline
\end{tabular}

${ }^{w}$ Wilcoxon test / p* Preop döneme göre kıyas / $p \neq$ Bir önceki ölçüme göre kıyas

NEU:Nötrofil, LYM: Lenfosit

Post-op 1. Saat, post-op 3.gün, postop 1ay PLT ve PDW değeri pre-op döneme göre anlamlı $(p>0.05)$ değişim göstermemiştir. Post-op 3.gün $P L T$ değeri post-op 1.saate göre anlamlı ( $p>0.05)$ artış olduğu gözlenirken post-op 1.ay $P L T$ değeri post-op 3.güne göre anlamlı ( $p>0.05$ ) değişim göstermemiştir (Tablo5 - Şekil 1 ve Şekil 2). 
Post-op 1. Saat, post-op 1.ay ve post-op 1.ay post-op 1. güne göre $P C T$ değeri preop döneme göre anlamlı $(p>$ $0.05)$ değişim göstermezken post-op 3.gün $P C T$ değeri pre-op döneme göre anlamlı $(p<0.05)$ artış ve post-op 3.gün, postop 1.saate göre anlamlı $(p<0.05)$ artış göstermiştir(Tablo 5 -Şekil 3)

Post-op 1. Saat, post-op 1.ay MPV değeri pre-op döneme göre anlamlı $(p>0.05)$ değişim göstermemiştir. Post-op 3.gün MPV değeri pre-op döneme göre anlamlı $(p<0.05)$ artı̧̧ göstermiştir. Postop 3.gün MPV değeri post-op 1.saate göre anlamlı $(p<0.05)$ artış göstermiştir. Post-op 1.ay MPV değeri postop 3.güne göre anlamlı $(p<0.05)$ düşüş göstermiş̧ir (Tablo 5-Şekil 4).

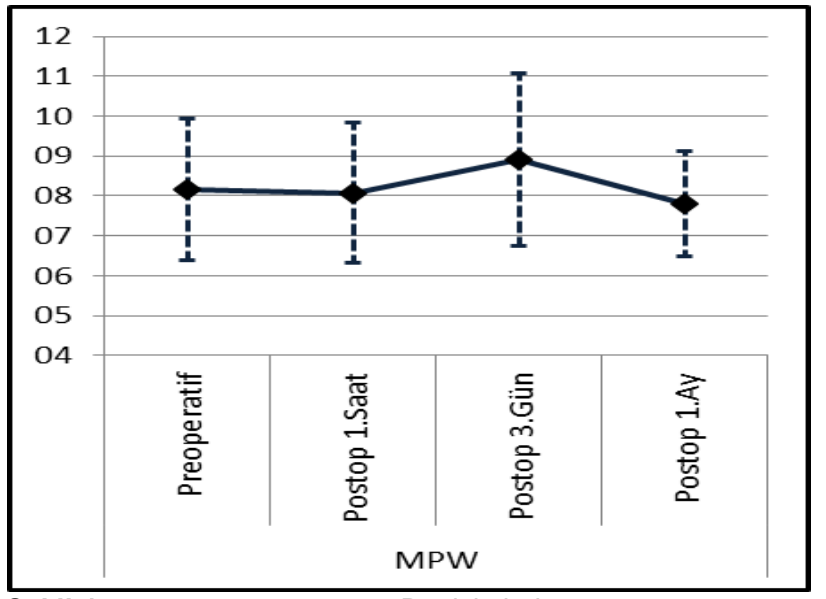

Şekil 4. Preop ve Postop MPV Değişimleri

MPV: Mean Platelet Volume

\section{Tartışma}

Kronik venöz yetmezlik ve varis tedavisinde endovenöz tedavi yöntemleri cerrahi travmalara maruz kalmadan minimal invaziv olmasına rağmen, anestezi için multipl perivenöz iğne enjeksiyonu prosedürel ağrı, ekimoz ve nöropatik hasarlara neden olabilmektedir. Ayrıca tüm escent anestezi uygulamak öğrenme eğrisinin en zor kısmıdır, zaman ve deneyim gerektirir(11, 12).

Son zamanlarda tümesan anesteziye ihtiyaç duymayan nontermal, nontümesan endovenöz tedavi yöntemleri geliştirilmiştir. Mekanokimyasal ablasyon ve CA tutkalı gibi. CA tutkalı yıllardır arteriovenöz malformasyonların ve peptik varikozitelerin tedavisinde insanlarda güvenle kullanılan sıvı bir yapıştırıcıdır.Bu yapıştırıcı kan ile temas ettiğinde plazma ve kan polimerizasyonunu uyarır ve damarın kapanmasını sağlar $(13,14)$.

Yapılan birçok çalışmada endovenöz safen ven ablasyonunun(CA veya Lazer ablasyon) güvenli olduğu gösterilse de nadirde olsa DVT ve tromboembolik olaylara rastlanmaktadır.Bu bazen kullanılan guide telinin tortiyoze safenven de endotel hasarı yapması, bazen de SFJ da güdük bırakılması sonucunda tromboembolik olaylar tetiklenebilir. Aynı zamanda işlemin uzun sürdüğü durumlarda kullanılan kataterlerin tromboembolik olayları başlatıyor olması da olası nedenlerdendir.

Literatür taramasında post-op komplikasyonları önlemek için DMAH (düşük molekül ağırlıklı heparin) rutin olarak önerilmemiş veya kaçınılması gerektiği bildirilmemiştir. Ancak yine yapılan literatür taramasında süperfisiyal ven trombozu sıklığı \% $05-\% 4$ arasında tespit edilmiş ve DMAH ile başarılı bir şekilde tedavi edilmiştir (15-19).

Yiu Che Chan ve arkadaşlarının 29 hasta ve 57 bacak ile yaptıkları bir çalışmada post-op 2 hastada derin venöz sistemde trombüs tespit etmişler ve bunları 1 haftalık LMWH ile tadavi etmişlerdir (20).

Biz İncelediğimiz 60 serilik hasta grubumuzun tümünde taburculuk sonrası bir haftalık profilaktik dozda DMAH başladık ve hiç bir hastamızda post-op kontrollerinde venöz tromboz veya pulmoneremboli gelişmedi.

Venöz tromboembolizm hemen hemen tamamı bacak venlerinde meydana gelir. Bunun en ciddi ve mortal komplikasyonu olan pulmoner emboli ven lümenindeki pıhtının kopup akciğer vasküler yatağına geçmesiyle oluşur. Etyolojide bacak venlerindestaz oluşturan her türlü olay rol oynayabilir. Bunun yanında cerrahi girişimler, ileri yaş ( $>50$ yaş), kırık ve yanıklar, obesite, minör cerrahi ve travmalar ve çeşitli sebeplerle üç günden fazla yatağa bağımlı kalma diğer tromboemboli sebeplerindendir.

Venöz tromboembolizm laboratuvar tanı yöntemleri daha çok ayıııcı tanıda ve pulmoner emboliyi desteklemek veya dışlamak için yapııır. Trombosit(=Platelet), ve diğer trombosit indeksleri olan PDW(trombosit dağılım genişliği), PCT(plateletcrit) ve MPW değerleri tromboembolik olaylarda artan indekslerdir. Normalde MPV ile PLT arasında ters bir ilişki vardır, PLT ne kadar düşükse MPV o kadar yüksektir. MPV'nin arteriyel tromboz, akut miyokart enfarktüsü, diyabet ve venöz trombo embolizm için önemli bir risk faktörü olduğuna dair kanıtlar vardır. MPV ayrıca farklı trombositopenik durumlarda bir tanı aracı olarak değerlendirilmiştir $(10,21)$.

PLT ve MPV'nin ölçümü ucuz ve kolaydır. Çoğu rutin klinik uygulamalarda kullanilır. Venöz ve arteriyeltrombozun akut fazında MPV'ün daha büyük olduğunu ve kötü klinik sonuçlara sebep olduğu bilinmektedir. Daha büyük trombositlerin daha genç olduğu, daha fazla adhezyon reseptörü ekspresyonuna sahip olduğu, daha fazla granül içerdiği, daha fazla metabolik ve enzimatik olarak aktif olduğu, kolajen ile daha hızlı toplandığı ve bu nedenle artmış trombojenik özelliklere sahip olduğu gösterilmiştir(22).

Bu trombositlerin daha geniş bir popülasyona doğru geçişini ve periferal kanda olgunlaşmamış trombositlerin daha yüksek bir oranı şeklinde açıklanabilir.Trombüs oluşumu 
anındaki yüksek seviyedeki trombosit döngüsü düşünüldüğünde, dolaşıma bırakılan trombositler doğal ortamlarında daha fazla trombojeniktir ve bu nedenle VTE ortamında daha yüksek seviyede MPV ile ilişkili istenmeyen prognozu açıklar(23).

National Library of Medicine ulusal Tıp kütüphanesine göre normal trombosit sayısı mikrolitre kan başına 150.000 ila 400.000'dir. MPV'nin normal değeri 7,5fL-11,5fL aralığındadır. Bu değerler trombositlerin 2,65 ile 2,8 mikrometre çapında olması anlamına gelir. $9.7 \mathrm{fL}-12.8 \mathrm{fL}$ aralığında MPV değerleri çoğunlukla sağlıklı olarak görülmektedir.

Tablo 5. Hastaları Pre op Post op PLT, PDW, PCT ve MPV Değişimleri

\begin{tabular}{|c|c|c|c|c|c|c|c|c|c|}
\hline & Min-Mak & & Medyan & Ort. \pm ss. & & $\mathrm{p}^{*}$ & & $p \neq$ & \\
\hline \multicolumn{10}{|l|}{$P L T$} \\
\hline Preoperatif & 98,9 & - 355,8 & 222,5 & 229,3 & $\pm 50,9$ & & & & \\
\hline Postop 1.Saat & 99,4 & - 363,4 & 211,1 & 222,5 & $\pm 55,3$ & 0,060 & w & & \\
\hline Postop 3.Gün & 24,8 & - 364,7 & 225,0 & 223,0 & $\pm 68,4$ & 0,536 & w & 0,186 & w \\
\hline Postop 1.Ay & 99,4 & - 359,8 & 220,9 & 228,9 & $\pm \quad 48,9$ & 0,729 & w & 0,828 & w \\
\hline \multicolumn{10}{|l|}{ PDW } \\
\hline Preoperatif & 7,0 & $-22,8$ & 17,9 & 18,7 & $\pm \quad 2,4$ & & & & \\
\hline Postop 1.Saat & 14,3 & $-22,5$ & 18,5 & 18,5 & $\pm 1,9$ & 0,571 & w & & \\
\hline Postop 3.Gün & 9,7 & $-22,7$ & 19,9 & 18,8 & $\pm 2,9$ & 0,480 & w & 0,156 & w \\
\hline Postop 1.Ay & 15,6 & $-\quad 22,8$ & 18,4 & 18,9 & $\pm 1,8$ & 0,777 & w & 0,800 & w \\
\hline \multicolumn{10}{|l|}{ PCT } \\
\hline Preoperatif & 0,11 & - 0,29 & 0,18 & 0,19 & $\pm \quad 0,03$ & & & & \\
\hline Postop 1.Saat & 0,09 & $-8,50$ & 0,18 & 0,32 & $\pm \quad 1,08$ & 0,249 & w & & \\
\hline Postop 3.Gün & 0,08 & - 9,83 & 0,20 & 0,36 & $\pm \quad 1,24$ & 0,016 & w & 0,000 & w \\
\hline Postop 1.Ay & 0,10 & $-0,31$ & 0,18 & 0,18 & $\pm 0,05$ & 0,627 & w & 0,075 & w \\
\hline \multicolumn{10}{|l|}{ MPW } \\
\hline Preoperatif & 5,6 & - 13,4 & 8,0 & 8,2 & $\pm 1,8$ & & & & \\
\hline Postop 1.Saat & 5,3 & $-14,4$ & 7,7 & 8,1 & $\pm 1,8$ & 0,702 & w & & \\
\hline Postop 3.Gün & 5,6 & $-13,7$ & 8,7 & 8,9 & $\pm \quad 2,2$ & 0,006 & w & 0,000 & w \\
\hline Postop 1.Ay & 5,4 & - 11,4 & 7,8 & 7,8 & $\pm 1,3$ & 0,334 & w & 0,002 & - \\
\hline
\end{tabular}

wWilcoxon test / p* Preop döneme göre kıyas / $p$ キ Bir önceki ölçüme göre kıyas

Çeşitli klinik durumların farklı meta-analizlerinde önemli derecede artmış MPV bildirilmiştir (24).Yapılan bir metaanalizde, VTE ile anlamlı derecede artmış MPV ve önemli ölçüde azalmış PLT saptanmıştır. Bu nispeten küçük fakat anlamlı farklılıkların klinik ilgisini araşıımak için ek çalışmalara intiyaç vardır. VTE olan hastalarda artmış MPV'nin neden mi yoksa venöz tıkanıkığın sonucu mu olduğunu belirlemek için daha ileri çalışmalar gereklidir.

Mevcut tüm otomatik hematoloji analizörleri MPV parametresini üretir. Bu parametre standartlaştırımamış olsa da, normal aralık 7-12 fL arasında değişmektedir. Son zamanlarda serbest bırakılan trombositler daha büyük ve hemostatik olarak daha aktiftir. Trombosit aktivasyonu trombosit şeklindeki değişikliklere ve artmış MPV ile sonuçlanan trombosit şişmesi (kürecik) artışına yol açar. Empedans analizörleri ile MPV ve PDW, trombosit dağılım eğrisinden türetilir ve bu nedenle, kullanılan antikoagülan, trombosit şişmesi ve numune analizinde olası zaman gecikmesinden etkileneceği için dikkatle yorumlanmalıdır.

Çalışı̆̆ımız seride post-op birinci saatte, üçüncü günde ve birinci aydaki PLT ve PDW değerlerinde anlamlı bir değişim gözlenmezken, MPV de post-op üçüncü gün değeri post-op birinci saate göre anlamlı artış göstermiş ve bu değer bir ay sonra tekrar düşerek post-op üçüncü güne göre anlamlı düşüş göstermiştir. Serimizde hastalardaki PCT değerleri incelendiğinde ise post-op üçüncü günde pre-op döneme göre anlamlı artış göstermiş ancak postop birinci aydaki MPW düşüşü PCT değerinde görülmemiştir.

CA ile yapılan safen ven embolizasyonunda ven içerisine çeşitli enstrümantal cihazlar yerleştirilir. Ayrıca CA kan ve doku ile temas ettiğinde polimerizasyona uğrar ve incompetent ven inoklüzyonunu sağlar. Ven içerisinde kısa bir segmentte(özellikle safenofemoral bileşkede)staz oluşabilir ve tromboembolik olayları başlatabilir (20).Tüm bunlar MPV ve PCT değerindeki değişimleri açıklayabilir.Özellikle son zamanlarda yapılan birçok çalışmada MPV ün tanısal 
değeri üzerine çeşitli sonuçlar yayınlanmışıı (25).Ancak unutulmamalıdır ki yapılan çalışmalar MPV seviyelerinde mevsimsel değişiklikler gösterebileceği gibi kullanılan cihazlar ve teknolojiler sapmalara yol açabilir. Kan örnekleri için antikoagülan türü de PLT üzerinde anlamlı bir etkiye sahiptir(26-28).

Çalıştı̆ımız serideki hastalarımızda pre-op antikoagulan alanların dışlanma sebebi işlem sırasında intravasküler enstrümantal cihazların (guide, sheath ve teslim katateri) manipülasyonları sırasında olası bir damar rüptüründe istenmeyen kanamaların önüne geçmekti. Başarııı işlemden sonrada tüm hastalarımıza bir haftalık DVT ve venöz tromboemboliye karşı, literatürdeki uygulamalara benzer şekilde, profilaktik dozda DMAH başlandı. (15-19). Bu çalışmada kontrendike olmayan hastalarda fayda-zarar hesabı esas alınarak, daha faydalı olabileceği düşünülen alternatif yol seçildi. CA ile variköz venlerin embolizasyonunda düşük dozda DMAH başlandı. Ancak unutulmamalıdır ki bu profilaksinin rutin hale getirebilmesi için prospektif ve daha geniş hasta serilerini içeren çalışmalara intiyaç vardır (29). Birçok literatür taramasında post-operatif komplikasyonları önlemek için DMWH rutin olarak önerilmemiş veya kaçınıması gerektiği bildirilmemiştir. Ancak yine yapılan literatür taramasında süperfisiyal ven trombozu sıklı̆ı $\% 05$ ile $\% 4$ arasında değiştiği tespit edilmiş ve DMWH ile tedavi edildiği belirtilmiştir (15-19).

Yine benzer şekilde,Yiu Che Chan ve arkadaşlarının 29 hasta ve 57 bacak ile yaptıkları bir çalışmada; post-op 2 hastada derin venöz sistemde trombüs tespit edildiği ve bu hastaları bir haftalık LMWH ile tadavi ettiklerini belirtmişler$\operatorname{dir}(20)$.

SONUÇ:Bu çalışma serimizdeki 60 hastanın hiçbirinde venöz tromboemboli veya pulmoneremboli vakasına rastlanmadı. Literatür taramasında da minimal invaziv varis tedavilerinde tromboembolik olaylar nadir görülmektedir. Ancak serimizdeki hastalarda MPV ve PCT değerlerinde özellikle 3. günde alınan kan örneklerinde anlamlı artış göstermiştir. Bunun ven içerisinde kullanılan enstrümental cihazlara bağlı olduğunu düşünüyoruz. Ayrıca polimerize olan CA'ın ve oklude olan vende meydana gelen stazında katkı sağladığı düşünülebilir. Bu nedenle varis tedavisinde $\mathrm{CA}$ kullanımında özellikle ilk günlerde tromboembolik olaylara karşı tedbirli davranılmalı ve hastalar düşük molekül ağırııkı heparin ile proflaksiye alınmalıdır.

Çalışmamızın retrospektif olması ve hasta sayısının azlığı ana kısıtılığı oluşturuyor. Prospektif ve daha geniş hasta sayısı ile yapılacak çalışmalarda MPV'ün CA ile yapılan safen ven embolizasyonunda tromboembolik olaylara etkisi konusunda daha iyi sonuçların alınabileceği aşikârdır.

\section{Kaynaklar}

1. Evan Evans CJ, Fowkes FG, Ruckley CV, Lee AJ. Prevalence of varicose veins and chronic venous insufficiency in men and women in the general population: Edinburgh Vein Study. J Epidemiol Community Health 1999; 53:149-153.
2. Yılmaz S. Venöz yetmezlik ve varis tedavisinde güncel yaklaşımlar. Klinik Gelişim 2010;23:57-62.

3. Dav G and Patrono C. "Platelet activation and atherothrombosis,"New England Journal of Medicine. 2007;357,(24);24822494.

4. Haver VM and Gear AR. "Functional fractionation of platelets," Journal of Laboratory and Clinical Medicine, 1981; 97( 2);187204.

5. Martin JF, Shaw T, Heggie J, and Penington DG. "Measurement of the density of human platelets and its relationship to volume," British Journal of Haematology, 1983;54 (33);337-352.

6. Koza, P. Grzela_zka, A. Trofimiuk et al., "Clinical risk factors for loss of stent primary patency in patients with chronic legs ischemia," Advances in Clinical and Experimental Medicine, 2017;:26(2);311-318.

7. Karpatkin S, "Heterogeneity of human platelets. VI. Correlation of platelet function with platelet volume," Blood, 1978;51 (2):307-316.

8. Chu SG, Becker RC, Berger PN et al., "Mean platelet volume as a predictor of cardiovascular risk: a systematic review and meta-analysis," Journal of 3rombosis and Haemostasis, vol. 8, no. 1, pp. 148-156, 2010.

9. Rao AK, Goldberg RE, and P. N. Walsh PN. "Platelet coagulant activities in diabetes mellitus. Evidence for relationship between platelet coagulant hyperactivity and platelet volume," Journal of Laboratory and Clinical Medicine.1984;103( 1): 82-92.

10. Kaya Z. Interpretation of automated blood cell counts. Dicle Medical Journal. 2013;40(3):521-528.

11. Chan YC, Ting AC, Yiu WK, et al. Cyanoacrylate superglue to treat varicose veins: Truly office based and inimally invasive? Eur J Vasc Endovasc Surg 2013;45:176-177.

12. Bozkurt AK, Yılmaz MF. A prospective comparison of a new cyanoacrylate glue and laser ablation for the treatment of venous insufficiency. Phlebology. $2016 \quad 31(1): 106-13$. doi:10.1177/0268355516632652.

13. Labenz J and Börsch $\mathrm{G}$. Bleeding gastric and duodenal varicose veins: Endoscopic embolisation using tissue adhesives. Dtsch Med Wochenschr 1992;117:1274-1277.

14. Brothers MF, Kaufmann JC, Fox AJ, et al. N-butyl-2cyanoacrilate substitute for IBCA in interventional neuroradiology: histopathologyc and polymerization time studies. Am J Neuroradiol 1989;10:777-786.

15. Tekin Al, Tuncer ON, Memetoglu ME, et al. Nonthermal, Nontumescent endovenous treatment of varicose veins. Ann Vasc Surg. 2016;36:231-235.

16. Koramaz I, El Kilıc, H, Gokalp F, et al. Ablation of the great saphenous vein with nontumescent nbutyl cyanoacrylate versus endovenous laser therapy. J Vasc Surg Venous Lymphat Disord.2017;5:210-215.

17. Tok M, Tuydes O, Yuksel A, et al. Early-term outcomes for treatment of saphenous vein insufficiency with N-Butyl Cyanoacrylate: a novel, nonthermal and non-tumescent Percutaneous Embolization Technique. Heart Surg Forum.2016;19:E118-E122

18. Çalık ES, Arslan Ü, Ayaz F, et al. N-butyl cyanoacrylate in the treatment of venous insufficiency-the effect of embolisation with ablative polymerisation. Vasa. 2016;45:241-246.

19. Bademci MS, Tayfur $\mathrm{K}$, Ocakoglu $\mathrm{G}$, et al. A new percutaneous technique: N-butyl cyanoacrylate adhesive for the treatment of giant saphenous vein insufficiency.Vascular. 2018;26:194-197.

20. Chan YC, Law Y, Cheung GC, et all. Cyanoacrylate glue used to treat great saphenous reflux: Measures of outcome. Phlebology Online First, published on April 6, 2016 as doi:10.1177/0268355516638200

21. Machin SJ, Briggs C. Mean platelet volume: a quick, easy determinant of thrombotic risk. J Thromb Haemost 2010;8(1):1467. 
22. Vizioli L, Muscari S, Muscari A. The relationship of mean platelet volume with the risk and prognosis of cardiovascular diseases. Int J Clin Pract 2009;63:1509-1515

23. Noris $P$, Melazzini $F$, Balduini $C L$. New roles for mean platelet volume measurement in the clinical practice? Platelets 2016;27:607-612.

24. Ren ZJ, Ren PW, Yang B, et all. Mean platelet volume, platelet distribution width and platelet count in erectile dysfunction: A systematic review and meta-analysis. Andrologia 2017;49(10)

25. Masutani R, Ikemoto T, Maki A, et all. Mean platelet component and mean platelet volume as useful screening markers for myelodysplastic syndrome Health Sci Rep. 2;1(5):1-6. doi:10.1002/hsr2.50

26. Moghadam RH, Shahmohammadi A, Asgari N, et all. Comparison of mean platelet volume levels in coronary artery ectasia and healthy people: systematic review and meta analysis. Blood Res. 2018;53(4):269-275. doi: 10.5045/ br.2018.53.4.269.

27. Beyan $\mathrm{C}$, Beyan $\mathrm{E}$. Were the measurements standardized sufficiently in published studies about mean platelet volume? Blood Coagul Fibrinolysis. 2017;28(3):234-6.

28. Kecskemetine G, Csiki Z, Mile M, Zsori KS, Shemirani ZAH. The clinical significance of pneumatic tube transport system on platelet indices: EDTA or citrate anticoagulant? Int J Lab Hematol 2017;39: 102-105.

29. Bissacco D, Stegher S, Calliari FM, Viani MP. Saphenous vein ablation with a new cyanoacrylate glue device: a systematic review on 1000 cases. Minim Invasive Ther Allied Technol. 2019 ;28(1):6-14. 